\title{
Influence of roof forms on the indoor thermal environment of rural houses in west China
}

\author{
Qiubo XIAO',a, Yu LIU', , Chen WANG ${ }^{2, c}$, and Jinghui MA ${ }^{2, d}$ \\ ${ }^{1}$ Sustainable Building and Environmental Research Institute, Northwestern Nontechnical \\ University, Xi'an, Shaanxi, 710072, China
}

${ }^{2}$ School of Civil Engineering and Architecture, Zhejiang Sci-tec University, Hangzhou, Zhejiang, 310018, China

a767554530@qq.com, bliuyu@nwpu.edu.cn, c584873559@qq.com, dmzh58@hotmail.com

Keywords: Roof form, Indoor thermal environment, Rural houses, China.

Abstract. SF roof (a sloping roof combined with a flat roof) is a special kind of roof existed in the west China. Based on Energy Plus software simulation, this paper investigated such roofs as well as normal flat roofs and sloping roofs of rural houses in the Ningqiang county of west China. It was found that, comparing to the normal flat roofs or sloping roofs, SF roofs in the researched region are more effective in maintaining a stable indoor thermal environment. Building models for the simulation of the research is introduced, results of the simulation are discussed and conclusions are provided.

\section{Introduction}

Along with the development of rural economy and government promotion of beautiful countryside construction, large amount of new rural houses have been constructed in west China during the recent 15-20 years and most of them are self-designed and self-constructed [1]. It was found that there are three typical forms of roofs in the Ningqiang region, which are the flat roofs, the sloping roofs, and a sloping roof combined with (adds on top of) a flat roof (Fig.1). In this paper, the third one is referred as SF roof. Considering that roof forms have great impact on the indoor thermal environment and energy consumption of rural houses, the influence of the above three typical roof forms on the indoor thermal environment of rural houses are compared based on software simulations.

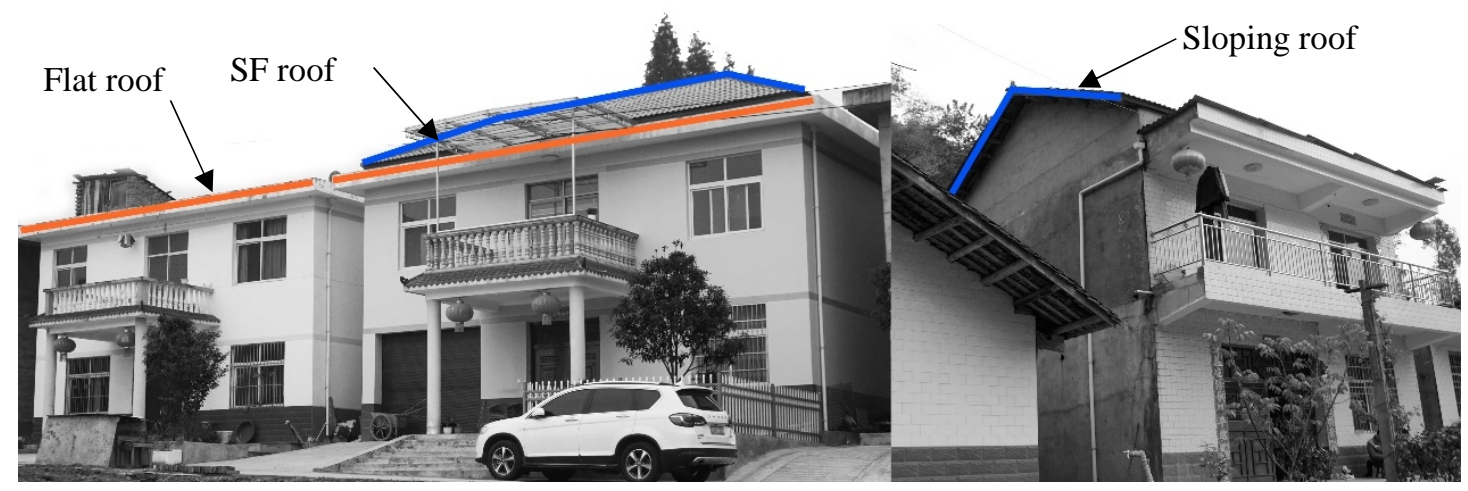

Figure 1. Three kind of roof forms in the Ningqiang

\section{Climate conditions of Ningqiang region in west China}

Ningqiang region locates at the "cold in winter and warm in summer" climate zone for building 
thermal design in China. Its summer mean temperature is about $22.7^{\circ} \mathrm{C}$ and the highest temperature in summer is about $37.4^{\circ} \mathrm{C}$ [2]. Feng and Dong [3] observed that, in the resent 50 years, the temperature of this region had showed a rising rate of $0.14^{\circ} \mathrm{C} / 10 \mathrm{a}$. The weather data recorded by the small weather station set by the research group of this paper showed that, in the summertime of year 2016, the average temperature was $24.7^{\circ} \mathrm{Cand}$ the highest temperature was $35.2^{\circ} \mathrm{C}$.

\section{Building models for the simulation}

Energy plus software was used to simulate the indoor thermal environment of rural houses in this research. Variable in the simulation is limited to the form of roof only. Essential settings of the building model are shown in Fig. 2. The models with three different roof forms are shown in Fig. 3 Basic parameters of the building models for simulation are shown in Table 1 . The different parameter of the three models is purposely limited to the form of the roofs.

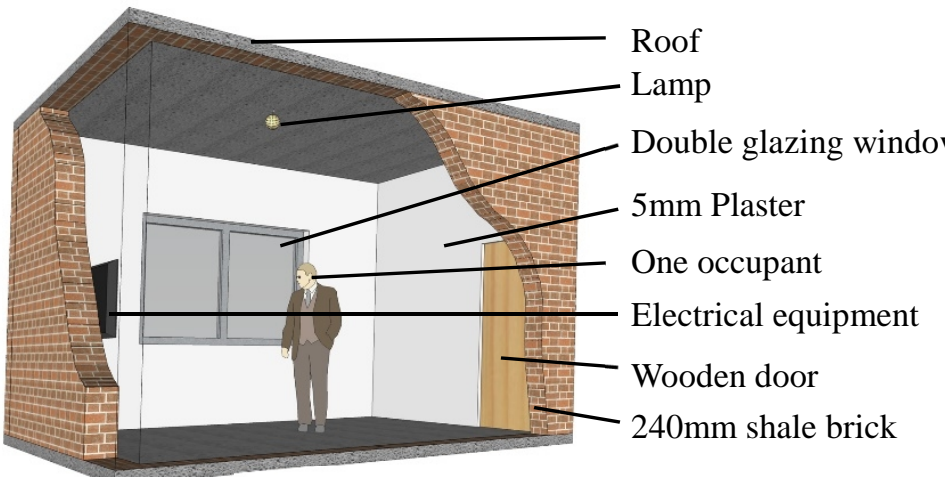

$3 \mathrm{D}$ view

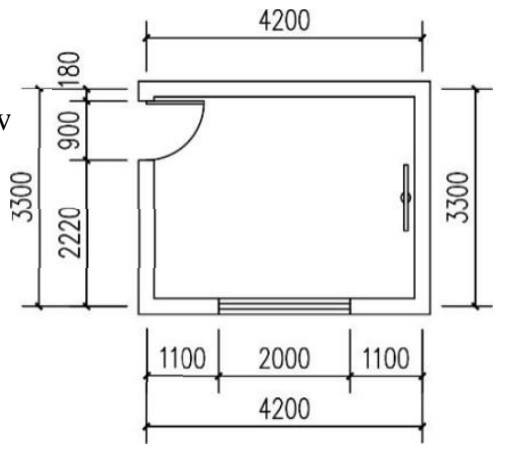

Plan

Figure 2. Settings of the building model for simulation

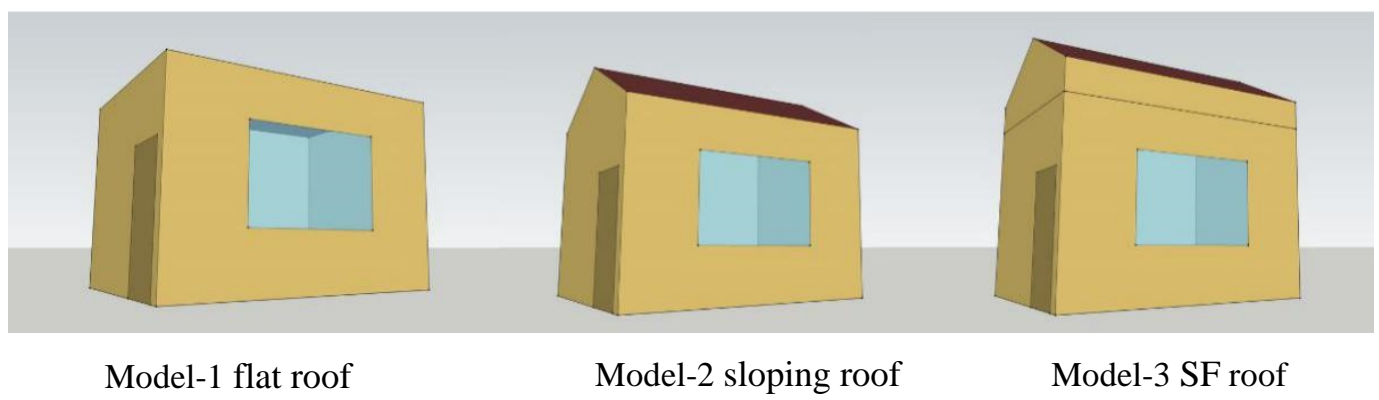

Figure 3. Models with three different roof forms

\section{Factors explored}

Factors explored through the simulation include daily mean temperature, daily maximum temperature, daily minimum temperature of the hottest period, and hourly temperature of the hottest week. The diurnal temperature range (DIT) was calculated based on daily maximum and minimum temperatures. According the collected weather data, the hottest period of Ningqiang region was set as between June 15th and August 31th, in which the hottest week was set as between July 27th and August 5th. 
Table 1. Basic parameters of the building models for simulation

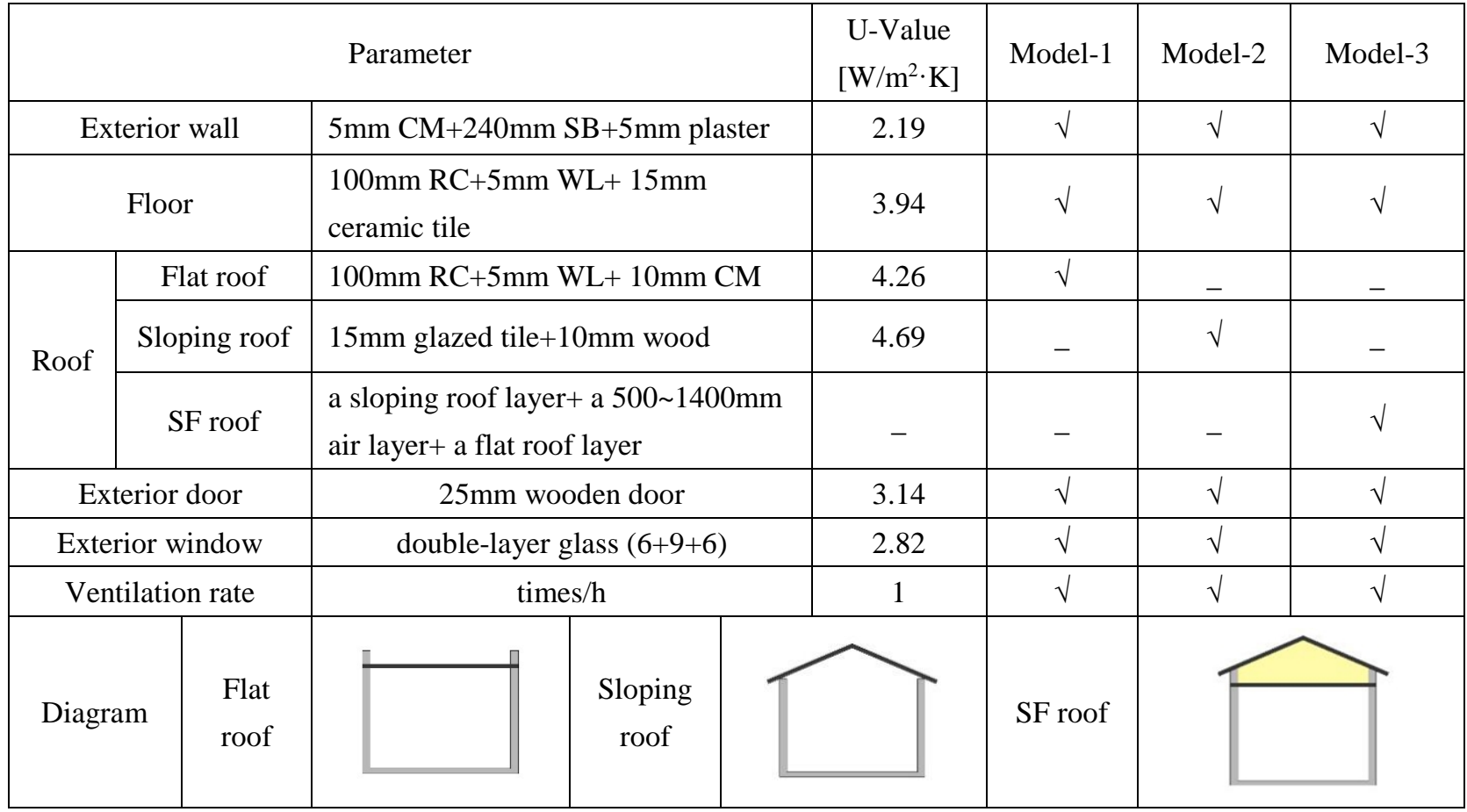

${ }^{\mathrm{a}} \mathrm{RC}=$ reinforced concrete. ${ }^{\mathrm{b}} \mathrm{WL}=$ waterproof layer. ${ }^{\mathrm{c}} \mathrm{CM}=$ cement mortar.

\section{Results of the simulation}

Results of the simulation show that, the variation of indoor temperatures of the three models are similar whether with or without inner heat gains. The hourly temperature curves in the hottest week (July 27th to 29th) (Fig. 4) reveal that: the highest daily temperature of model-3 is lower than that of model-1and model- 2 and its daily temperature changes are also more gentle comparing to that of the other two models.

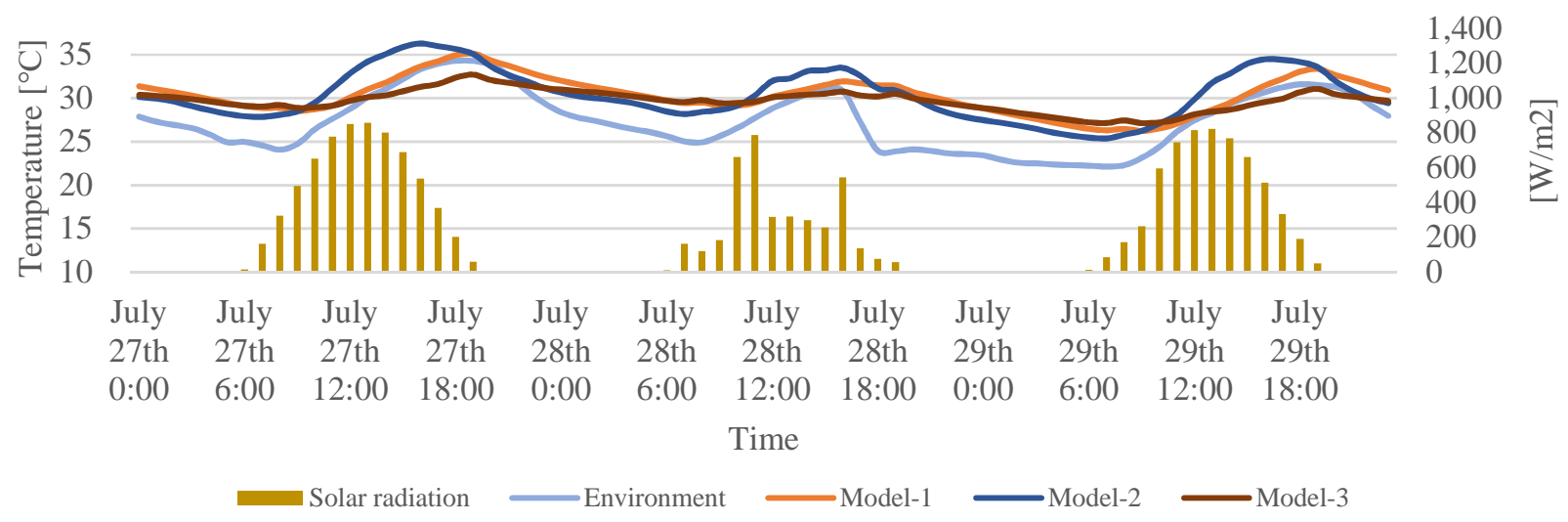

Figure 4. Hourly temperatures of the hottest week

More results of the simulation are listed in table 2. It showed that, under the same circumstances, ADIT, BDIT \& MHO of model-3 are obviously lower and the occurrence time of HITs \& LITs are later than those in the other two models. It also revealed that, in terms of indoor temperature stability, SF roof (model-3) is the best followed by flat roof (model-1), sloping roof (model-2) is the worst.

Discussion of the above results concentrated on the constitution of the SF roof itself. It is conjectured that: first, glazed tiles on top of the sloping roof can block much of solar radiation; then, the air layer between the flat and sloping roofs perform as a buffer zone, which can help to further 
reduce heat transfer; thirdly, when heat passes the flat roof, which is made of $100 \mathrm{~mm}$ thick concrete, its influence on the indoor thermal environment is already greatly reduced.

Table 2. List of the simulation results

\begin{tabular}{|c|c|c|c|c|c|c|c|c|c|c|}
\hline Unit & {$\left[{ }^{\circ} \mathrm{C}\right]$} & Indoor & Environment & ADIT & BDIT & MHO & HIT & Time(HIT) & LIT & Time(LIT) \\
\hline \multirow{4}{*}{\begin{tabular}{c} 
Nature \\
\cline { 2 - 11 }
\end{tabular}} & Model-1 & 27.14 & 25 & 4.83 & 7.65 & 2.14 & 34.17 & $18: 00 \mathrm{pm}$ & 27.97 & $8: 00 \mathrm{am}$ \\
\cline { 2 - 11 } & Model-2 & 27.26 & 25 & 6.77 & 9.85 & 2.26 & 35.93 & $16: 00 \mathrm{pm}$ & 27.38 & $8: 00 \mathrm{am}$ \\
\cline { 2 - 11 } & Model-3 & 26.64 & 25 & 2.75 & 4.38 & 1.63 & 31.53 & $19: 00 \mathrm{pm}$ & 28.24 & $9: 00 \mathrm{am}$ \\
\hline \multirow{3}{*}{$\begin{array}{c}\text { Heat } \\
\text { gain }\end{array}$} & Model-1 & 27.75 & 25 & 5.21 & 8.11 & 2.75 & 35.11 & $19: 00 \mathrm{pm}$ & 28.53 & $9: 00 \mathrm{am}$ \\
\cline { 2 - 11 } & Model-2 & 27.79 & 25 & 6.86 & 9.85 & 2.79 & 36.28 & $16: 00 \mathrm{pm}$ & 27.86 & $7: 00 \mathrm{am}$ \\
\cline { 2 - 11 } & Model-3 & 27.32 & 25 & 3.23 & 5.11 & 2.32 & 32.7 & $19: 00 \mathrm{pm}$ & 28.88 & $9: 00 \mathrm{am}$ \\
\hline
\end{tabular}

Note: ${ }^{\mathrm{a}} \mathrm{ADIT}=$ average diurnal temperature. ${ }^{\mathrm{b}} \mathrm{BDIT}=$ biggest diurnal temperature. ${ }^{\mathrm{c}} \mathrm{MHO}=$ mean temperature that is higher than the outdoor temperature. ${ }^{\mathrm{d}} \mathrm{HIT}=$ highest indoor temperature. ${ }^{\mathrm{e}} \mathrm{LIT}=$ lowest indoor temperature.

\section{Conclusions}

For buildings in the "cold in winter and hot in summer" climate zone of west China, roof forms have demonstrable influence on the indoor thermal environment. SF roofs in the Ningqiang region create a buffer zone between building and their outdoor environment therefore can improve heat-insulation level of the building. Results of software simulation in this research indicate that, comparing to the normal flat roofs and sloping roofs, SF roofs are more effective in reducing the diurnal temperature difference and delaying the occurrence time of the maximum and minimum indoor temperatures. In other words, they are more effective in maintaining a stable indoor thermal environment so are more helpful in achieving good thermal comfort levels \& living experiences of local residents.

\section{Acknowledgments}

The research of this paper was sponsored by the Seed Foundation of Innovation and Creation for Graduate Students in Northwestern Nontechnical University (Z2017122), 2016 International Science and Technology Collaboration and Communication Program of Shaanxi Province (No.2016KW-031), and the 12th Five-Year Science and Technology Support Program of China (2015BAL03B04-2).

\section{Reference}

1. Li, Y., J. Wang, and J. Den, A preliminary study on the climate adaptive design of green rural houses in west China. Proceeds Engineering, 2017. 180(2017): p. 735 - 740.

2. H, J., X. Lu, and J. Nu, Analysis on the climatic characteristics in the recent 51 years of Ningqiang County. Shanghai Meteorology, 2010. 2010(3): p. 18-21.

3. Feng, C. and J. Dong, Temperature and precipitation change characteristics in south region of Shanghai Province in recent 47 years. Journal of Arid Land Resources and Environment, 2011. (2011)08: p. 122-05. 